\title{
16
}

\section{Along the roads of the Lapita people: Designs, groups and travels}

\author{
Arnaud Noury
}

\begin{abstract}
A new set of rules that allows the division of Lapita designs into two distinct corpora is described. As a result, it is now possible to distinguish for a vast majority of designs-and not only the specific 'group marker' designs - precisely to which corpus and which 'group' they belonged. The implications of these results are significant: they confirm the existence of several dozen small groups of potters, each of them exclusively using a given corpus. The rules can also assign, with some confidence, each decorated sherd to a given group. This method of identification and attribution helps to track these groups in the Pacific, including their interactions over time. The distribution of Fijian, Tongan and Samoan designs is taken here as a test to demonstrate the model's reliability.
\end{abstract}

\section{Introduction}

Lapita pottery motifs are perhaps the best-known elements of the archaeology of the Lapita Cultural Complex. The motifs are complex and many, and they have been subject to numerous analyses, theories and methodologies since the 1960s (Anson 1983, 1986; Chiu 2003, 2005, 2007, 2010; Chiu and Sand 2005; Green 1979; Mead 1975; Noury 1998, 2000, 2005, 2011, 2013; Siorat 1988; Sharp 1988; Spriggs 1990). Chiu suggested in 2005 that some Lapita motifs related to group symbols, or social status. At the same time, my research led me also to identify designs that could be symbols of Lapita groups, although they are not exactly the same motifs as those identified by Chiu. Since then I have tried to identify all markers of potential Lapita groups throughout the Lapita world (Noury 2005, 2011, 2013; Noury and Galipaud 2011). Technically speaking, the markers are primarily patterned into squares (or circles in large units associated with faces). Inside the square, the variants are multiple, including mixing between the motifs, or degraded motifs (crosses, semicircles, circles in varying number, made with one or more lines, see Figure 16.1). This led me to suggest that these 'group markers' could be symbols for 'extended families' and that we should try and specify their precise nature. In theory, it was hoped to be able to follow these extended families through their voyages across the Pacific Ocean (see Noury 2011 for a detailed discussion).

Previously, I have identified five groups of large designs (Noury 2005, 2011). Each of them can be represented as multiple variants of each of the elements of which they comprise (Figure 16.2). These variants give an impression of great variety of decoration, but it seems that they were 
carried out according to very clearly defined rules. However, were these rules governed by the potters themselves, or by the groups, and is time and/or place also influential? This is what is interesting to try to determine. It seems that it is possible to isolate motifs of distinct groups among the various archaeological sites. My belief is that it is possible to track the movements of Lapita 'families' over time and space fairly accurately. Of course, there are also a lot of extra friezes, placed either above or below (or even inside) the pot rims, in addition to the core of group designs in the largest decorations. These complicate the readability of the decorations that are often only known by very fragmentary sherds. I have sorted most friezes into groups, differentiating them by variants (single, double, triple lines, presence of circles, etc.). Ultimately, it becomes apparent that there are not a lot of different friezes. They are primarily the same, but in forms that vary only slightly. Furthermore, I have been able to demonstrate that some of these friezes were used with some large primary individual designs, and not with others. This provides an analytical framework and a general summary of the main compositions that appeared on the pottery.
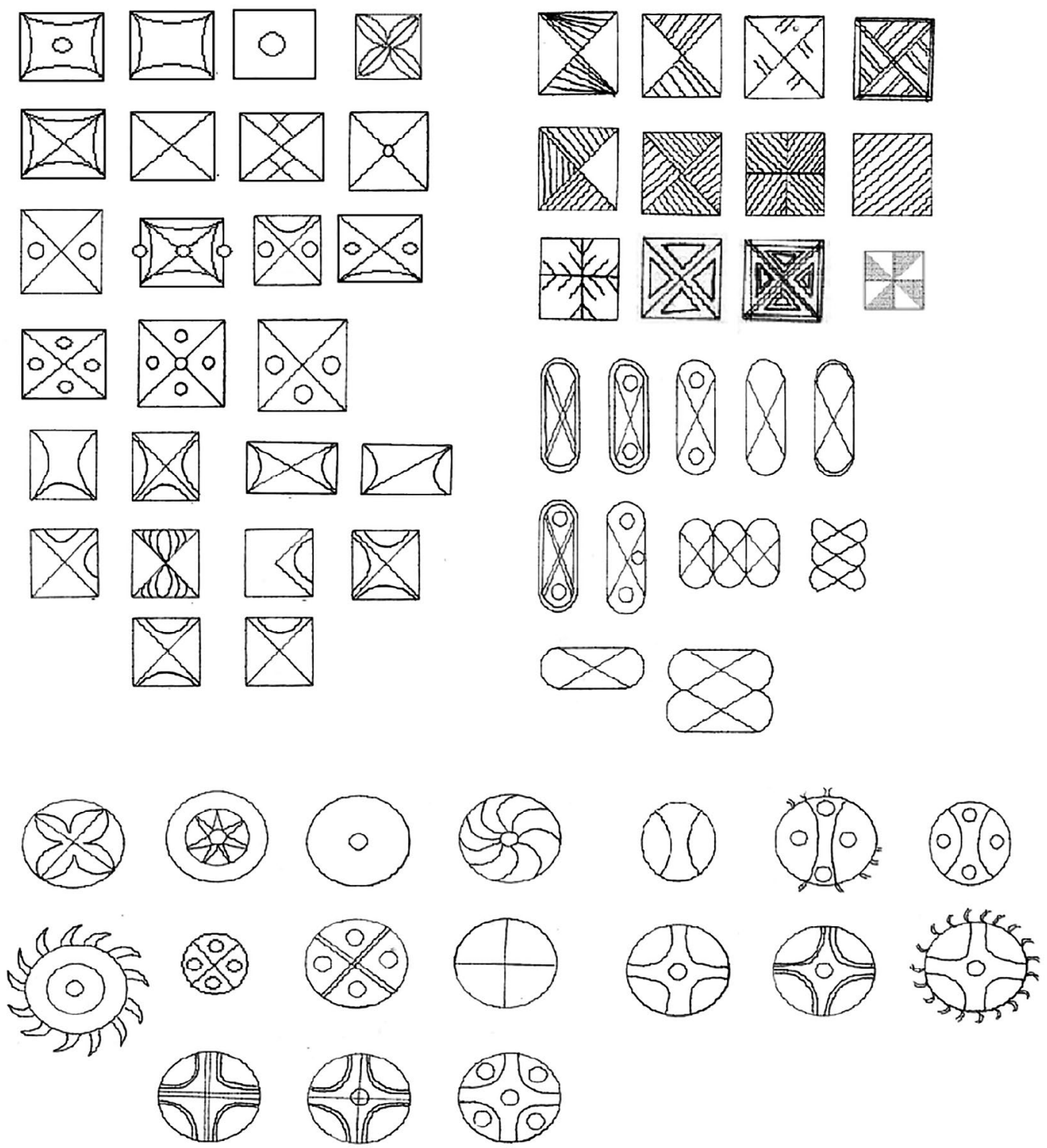

Figure 16.1. Main Lapita markers. Motifs can be drawn inside a square, a circle or even an oval. Source: Illustration by the author. 


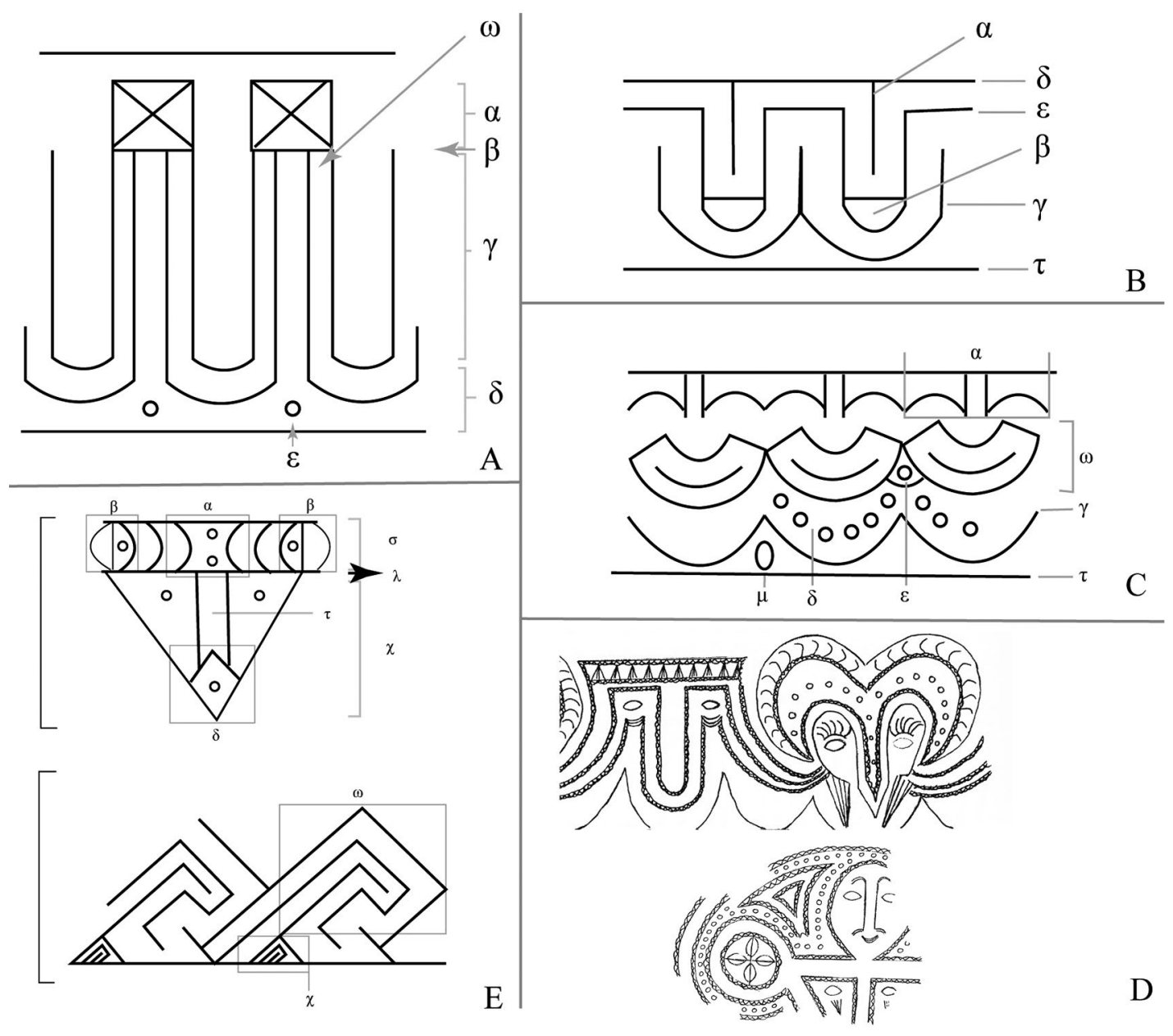

Figure 16.2. Five main large designs of Lapita pottery.

(A) composite-vertical (CV); (B) $\delta$-CV; (C) composite-ondulé; (D) large face; (E) composite oblique (typology used by the author). Source: Illustration by the author.

As far as can be deduced from previous work (Noury 2005, 2011, 2013), there were only a few large primary decorations. There are always the same pictures on Lapita pottery. But these few compositions have existed in many forms. The internal details, friezes and mode of representation generated many unique motifs, which are found in excavations, and hundreds of different motifs have been recorded (e.g. Anson 1983). However, it seems that the number of combinations is only on the order of 10 or 12 types at the most. Once these parameters have been established, we can begin to think about the best ways of studying Lapita pottery. Again, we return to the core questions: were there any spatial or temporal patterns, or were there other factors influencing the Lapita potters?

Based on the general principles outlined above, it would be interesting to explore more deeply the nature of differences in Lapita decorations. In this present study, therefore, I present an identification and spatial tracking test of different groups of Lapita potters. Two tools are used: a maximum distribution of motifs into two corpora of decorations, which is a kind of polarisation of the decorations, and the distribution of the group markers that are only a part of the total number of units. The chosen area to test these analytical tools is the Eastern Lapita Province, because it is relatively geographically isolated from the rest of the Lapita world. The ideal goal is to determine the movements of the different Lapita groups based on pottery decorations in this region. 


\section{Method and sources}

\section{Method}

The method used to identify Lapita groups was developed in different stages: at first, I had to collect all the motifs and standardise their representation. Then I started to establish links between sites from simple observation. Indeed, I had previously noticed (Noury 2011) that some designs appeared to spread differently in different geographical regions. These designs are not identical, but very similar: the 'double-curved', 'zigzag' and 'nose' forms (pointed or rounded) in large designs named 'composite oblique' (Figure 16.2E). These two pairs of motifs seemed to be clearly differentiated in the archaeological sites. I attempted to understand if they were each members of styles or of Lapita groups. By flipping through all the available graphic documentation, I adopted the basic criteria of 'if the motif $A$ is decorated with an $X$ and not $Y$, then $A$ and $X$ are together'; however, 'if the motif $\mathrm{A}$ is with both $\mathrm{X}$ and $\mathrm{Y}$, then $\mathrm{A}$ does not belong to each of the two sets'. Very obviously and very quickly, two large groups of designs were formed (named 'A' and 'B', see Figure 16.3). On the one hand, there are designs that have the double curve and sharp nose, and on the other there are those related to the zigzag and bent (curved) nose. Surprisingly, group markers were also separated within these divisions.

These results led to the following hypothesis: there were in the Lapita period two different primary decorative corpora, and a third that was shared by both. In addition, each corpus consisted of two sets of motifs from specific and determined Lapita groups. There was also much potential for mixing and creating motifs. These variations seem to have been based on how much a 'new Lapita group/new potter' retained the original corpus, and how much mixing was carried out with one part or another of the second corpus (Figure 16.4). Being aware of this, it is quite clear that one can start studying each archaeological collection with this division of the designs. The first detailed and thorough task required is to determine each component of different corpora. This is then followed by the analysis of the composition of the decorations of each archaeological site.

A

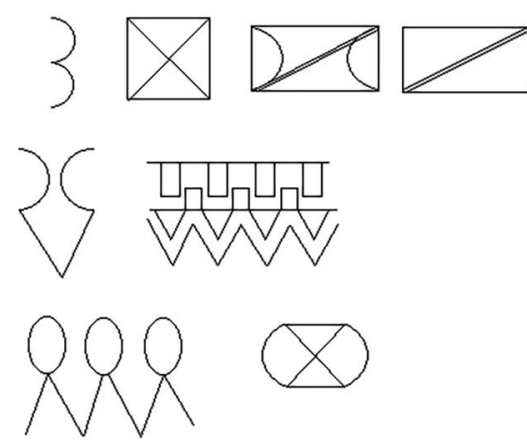

B

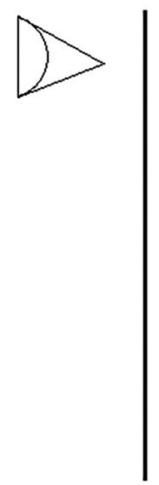

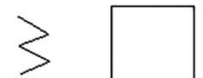
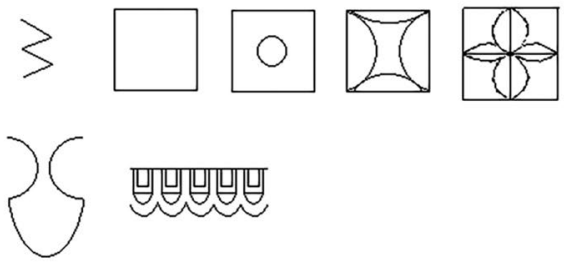

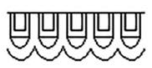

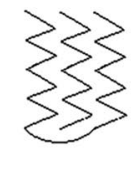

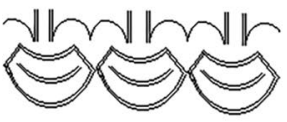

Figure 16.3. Main motifs of the two generic groups. Corpus A (left) and B (right).

Source: Illustration by the author. 


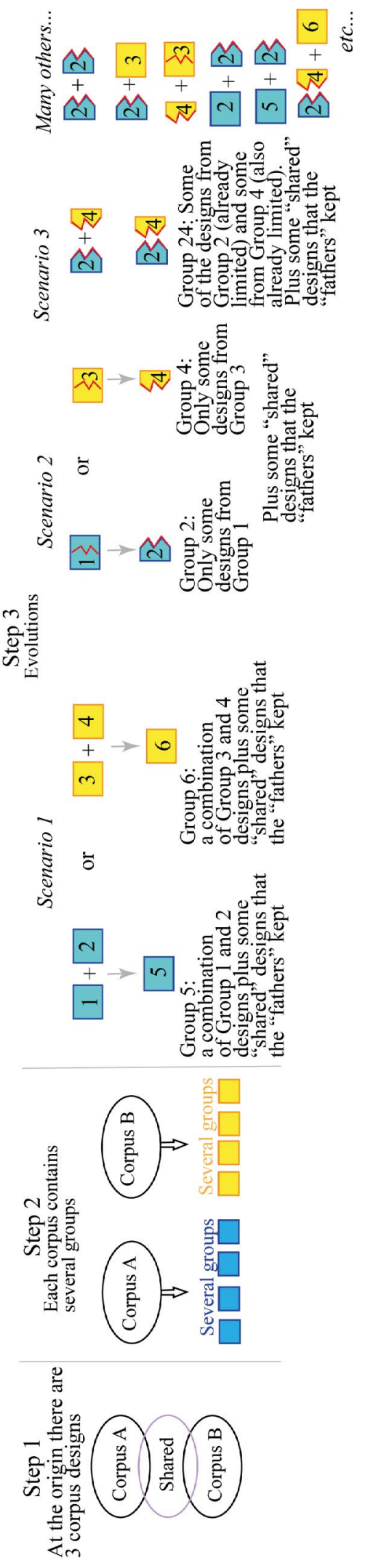

Figure 16.4. Theoretical view of how Lapita potters could have used corpus motifs.

Source: Illustration by the author.
To test this methodology for this present analysis, I first separated the motifs of Fijian, Tongan and Samoan sites to determine their connection to one of the two major generic corpora. This allowed an overview of the distribution of the two major corpora in the region. Second, the analysis focused on the presence of group markers in each site. How were they distributed? What were their links with the two major generic groups? What were the other Lapita motifs related to each group marker? For this, some decorated sherds offered clues: some group markers also had other motifs on the sherds. Then we were able to link group markers to some specific motifs. And then we could link these latter to other motifs again, and so on. At the end of this analysis there was quite a complete range of motifs included in the corpus of a Lapita group (and these Lapita groups themselves attributed to either ' $\mathrm{A}$ ' or ' $\mathrm{B}$ ').

Not all motifs have been assigned with certainty to one or other of the large corpora, and therefore to a specific group marker. Either these patterns were common to different groups, or the data are too partial in the corpus studied. Faced with these data that contain many gaps, we do not always have the potential to determine properly the assignation of all the motifs to one group. However, it is important to remember that this method has the advantage of following motifs in a large set of archaeological sites, without the results being heavily biased by the absence of some motifs. (It is a truism that a lack of evidence is a principle in archaeology, and therefore it is important to develop methods that have the advantage of highlighting the positive information provided by the presence of artefacts.) As we follow motif by motif, the presence of a design belonging to a Lapita group shows that at least some of the pottery of a particular group is determined by its locality. 
To sum up, the motifs were classified progressively: (1) in large generic groups 'A', 'B', or 'common' and 'indeterminate'; then (2) the links of each pattern to a 'group marker' were determined whenever possible. Finally, distribution areas of Lapita groups were established that involved transmission, if we consider that it is these motifs that have circulated as a diffusion of ideas, or actual people (potters) who circulated with the motifs. I support the latter hypothesis. It also has a significant impact on the interpretation of the results (see Noury 2011).

\section{Sources}

As noted above, the decorations used for the analysis were extracted from the collections of the Eastern Lapita Province. The sources are rather heterogeneous: they are sometimes direct observations, and sometimes reports and publications where motifs can be found under the form of the design indexes of Mead (1975), Anson (1983) and Poulsen (1987). In rare cases, some decorations were completely represented in photographs or drawings. The references used for Fiji included the sites of: Yanuca (Anson 1983: Table XII), Natunuku (Anson 1983: Table XII; Davidson et al. 1990), Naitabale (Nunn et al. 2007), Tavua (Cochrane et al. 2007), Ugaga and Kulu on Beqa Island (Anderson and Clark 2006), Vorovoro (Burley 2012), Naigani (Cochrane 2002; Cochrane et al. 2007 after Kay 1984), Votua or Wotua (Clark and Anderson 2001), Qaranipuqa (Best 1984) and Bourewa from direct observations made of decorated potsherds provided by Nunn (Patrick Nunn pers. comm. 2007, 2008). From the archipelago of Tonga, the site of Nukuleka is well documented (Anson 1983; Burley et al. 2002; Green 1990; Poulsen 1987), as is Faleloa (Burley 1991, 1992, 1994) and Lolokoka (Kirch 1988: Table 29; Rogers 1974). For the Samoan archipelago, sites studied were Mulifanua (Petchey 1995: Tables 3-5) and the Asipani Lapita site on (East) Futuna Island (Sand 1993).

These data are difficult to handle for a comprehensive analysis because of their heterogeneous nature. In addition, the quantities of sherds recovered also vary widely. Another key component of the data that is also largely missing, except from Bourewa, is the association between different motifs, which the Mead, Anson and Poulsen indexes do not provide. Other decorated sherds have also been discovered during recent excavations but have not yet been published. Undoubtedly, they will provide further help to clarify and correct the following analysis.

\section{Results}

\section{Polarisation in the Eastern Lapita Province}

Table 16.1 shows the distribution of Corpora $\mathrm{A}$ and $\mathrm{B}$ in all sites in the region. Two remarks must be made: first we can see that Corpus A is present everywhere. However, Corpus B is only present in Viti Levu and some surrounding islands, and further east on Lakeba and Tongatapu. Corpus B dominates in only three sites in the west of Fiji. The presence of two corpora found together in seven sites is not surprising. It probably comes from the settlement of the two potting corpora in one place. At Bourewa, for example, it seems that some excavation areas are clearly dominated by one corpus over another. It is likely that sites that have only one corpus may also contain motifs of the other corpus. Indeed, the small number of decorated potsherds discovered in these sites weakens many of the results, so that they can only be considered as provisional at this stage. 
Table 16.1. Presence/absence of Corpora A and B in the Lapita sites studied.

\begin{tabular}{|c|c|c|c|}
\hline Region & Site name & Corpus A & Corpus B \\
\hline \multirow[t]{11}{*}{ Fiji } & Yanuca & $x$ & $x$ \\
\hline & Natunuku & $x$ & $x$ \\
\hline & Bourewa & $x$ & $x$ \\
\hline & Naitabale & $x$ & $x$ \\
\hline & Naigani & $x$ & $X$ \\
\hline & Ugaga & $X$ & - \\
\hline & Kulu & $x$ & - \\
\hline & Vorovoro & $\mathrm{X}$ & - \\
\hline & Votua & $\mathrm{X}$ & - \\
\hline & Tavua & $x$ & - \\
\hline & Qaranipuqa & $x$ & $x$ \\
\hline \multirow[t]{3}{*}{ Tonga } & Nukuleka & $x$ & $x$ \\
\hline & Faleloa & $\mathrm{X}$ & - \\
\hline & Lolokoka & $\mathrm{X}$ & - \\
\hline Samoa & Mulifanua & $x$ & - \\
\hline Futuna & Asipani & $x$ & - \\
\hline
\end{tabular}

The corpus representing the highest proportion is in bold.

Source: Author's summary.

Importing a single pot of a corpus can 'contaminate' a site belonging to another corpus. The analyses of chemical components of some decorated sherds of the Naitabale site (Dickinson and Nunn 2013; Nunn et al. 2007) illustrate this phenomenon quite clearly. The analysis showed chemical composition of four different types: a first local (or standard) temper (71 per cent), a second originating from Viti Levu (11 per cent, quartzose), a third perhaps originating from Kadavu (11 per cent, feldspathic) and the last possibly originating from the Lau Islands (7 per cent, placer). Some decorated sherds are included in this analysis and we can attribute them to both corpora (but again quantities are low): the local sherds are mostly from Corpus B, the quartzose from Corpus $\mathrm{A}$, the feldspathic from Corpus B and the placer might be from Corpus B (without certainty for the latter). It would mean that while most of the decorated sherds are from Corpus B, a few (11 per cent) are from Corpus A and originated from Viti Levu. That also means that most of the exogenous decorated sherds (18 per cent) are from the same corpus as the local one in Naitabale, and 89 per cent of all decorated sherds are from the same corpus. It would be interesting to conduct the same kind of analysis for the sites of Bourewa and Nukuleka where sherds are numerous and both corpora are present. It would help confirm whether exogenous corpora are the same as the local one.

\section{Detection of group markers by site}

To better visualise the distribution of Corpora A and B and their possible correlations with the group markers, we can identify a dozen major groups by sites (Figure 16.5) (see Noury 2013: Chapter 4 for details). It thus appears that at least three major group markers appear in a rather recursive way (green, orange and blue squares in Figure 16.5). The remaining markers appear to be present primarily in the Fiji Islands only. We can note that this is far from being the full range of Lapita group markers. As far as can be established from published papers, many of those known in other archipelagos are missing. This corresponds to the fact that a smaller number of Lapita motifs were known in the Eastern Province. 


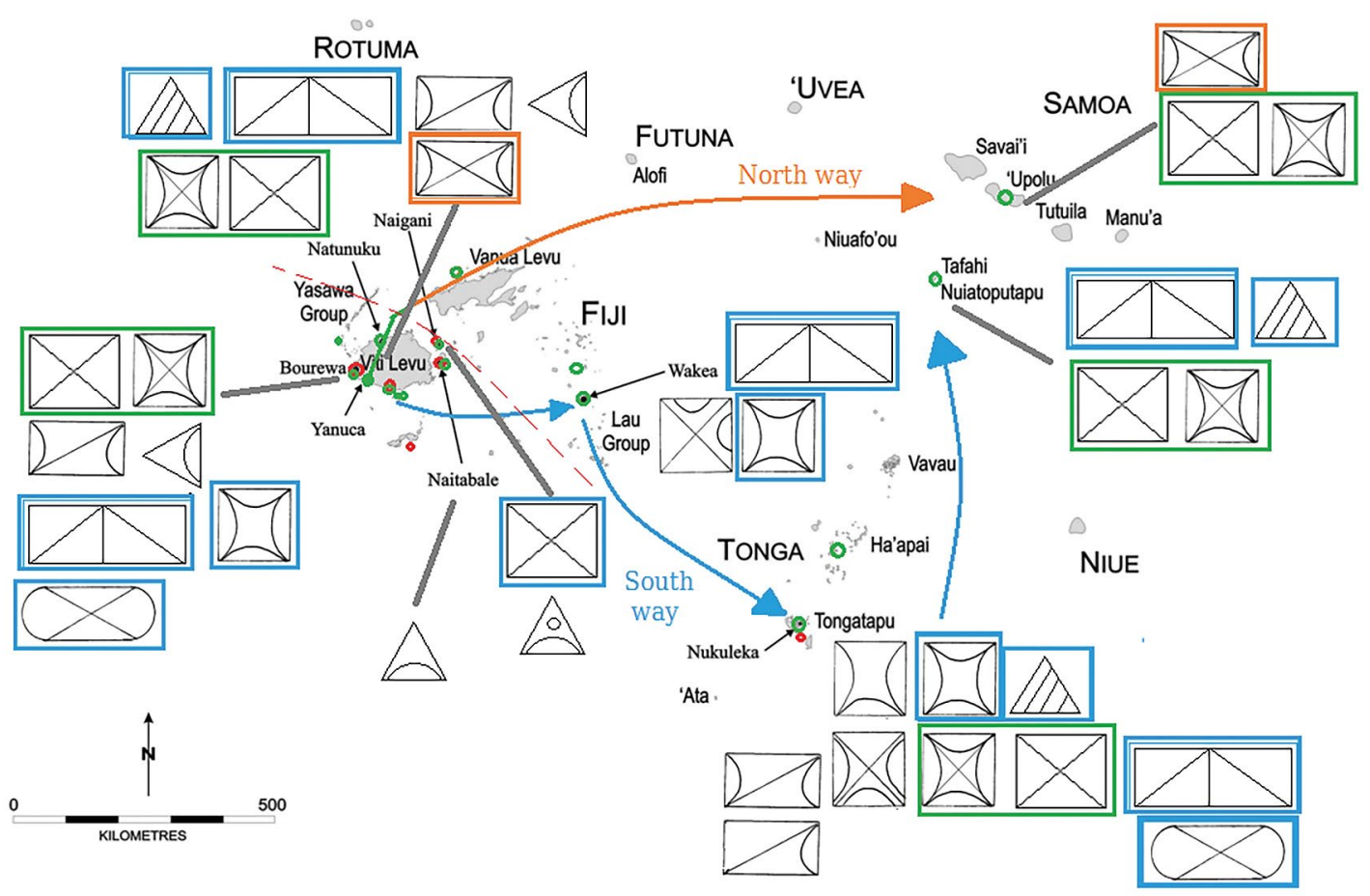

Figure 16.5. Main Lapita group markers in the Eastern Province.

Corpus A: green circle; Corpus B: red circle; in blue-green-orange squares: same markers. Arrows are hypothetical routes of Lapita potters.

Source: Illustration by the author.

It seems that a series of new group markers can be identified in this province (Noury 2013:97, Figure 168) and it means that some new groups were created there. Moreover, although some markers seem to have been directly derived from Reefs-Santa Cruz (Solomon Islands) collections (Noury 2013:100, Figure 169), others have links to a few samples in the Bismarck and Vanuatu archipelagos. These two points match very well with the same kind of distribution of the other motifs in the sites.

Another point is also significant. Both the Bourewa and Nukuleka sites have the largest quantities of group markers. Here there are two possibilities of interpretation. One is that both collections have high quantities of sherds relative to the others, implying a sampling bias in the analysis, although it must be said that the quantities of sherds from many of the other sites are not insignificant (e.g. Natunuku, Wakea, Yanuca). Alternatively, it may result from more groups travelling to or settling at both sites. A definitive answer to this question cannot be provided, but Nukuleka has been argued as being the primary and focal settlement in Tonga (Burley and Dickinson 2001; Burley et al. 2010). It has long been argued that this same type of phenomenon, a series of nodal settlements, must occur throughout the Lapita world. There are important sites that appear to have functioned as 'nodes' between different Lapita groups (Nenumbo for example, see Green 1976; Sheppard et al. 2015.) The same kinds of nodal settlements appear to have been present in the Eastern Province (cf. Burley et al. this volume). 


\section{Discussion}

What does this polarisation or divergence of Corpora A and B mean? Both corpora were produced by Lapita potters, but while Corpus A seems widely distributed (Figure 16.6), Corpus B seems never to have reached Samoa and was mostly restricted to western Fiji. In other words, the more Lapita spread eastwards, the less important was the number of motifs. Hence the impression of 'simplification' of the decorations, as long noted by Green (1979) and others. But this effect may have been due to a decrease in the number of groups who settled within the eastern geographical distribution, a bottleneck effect rather than being wholly temporally influenced. On the basis of Corpora A and B only, we cannot say from where the Lapita people ultimately originated. Both existed in other archipelagos but, based on group markers and motifs identified in each group, we can have some more precise, although patchy, ideas as to proximate origins. We saw above that some motifs and markers seem to have been created from motifs originating from the Reefs-Santa Cruz Islands, whereas others seem to have also included motifs with origins in Vanuatu. This indicates that groups in the Eastern Province have multiple origins. Additionally, it can be shown that many new motifs created in the Eastern Province never occurred in the other provinces. We might speculate then that there was mostly a 'one-way road' for motifs, a 'road' that led primarily towards new sites and much more rarely returned to previously settled ones.

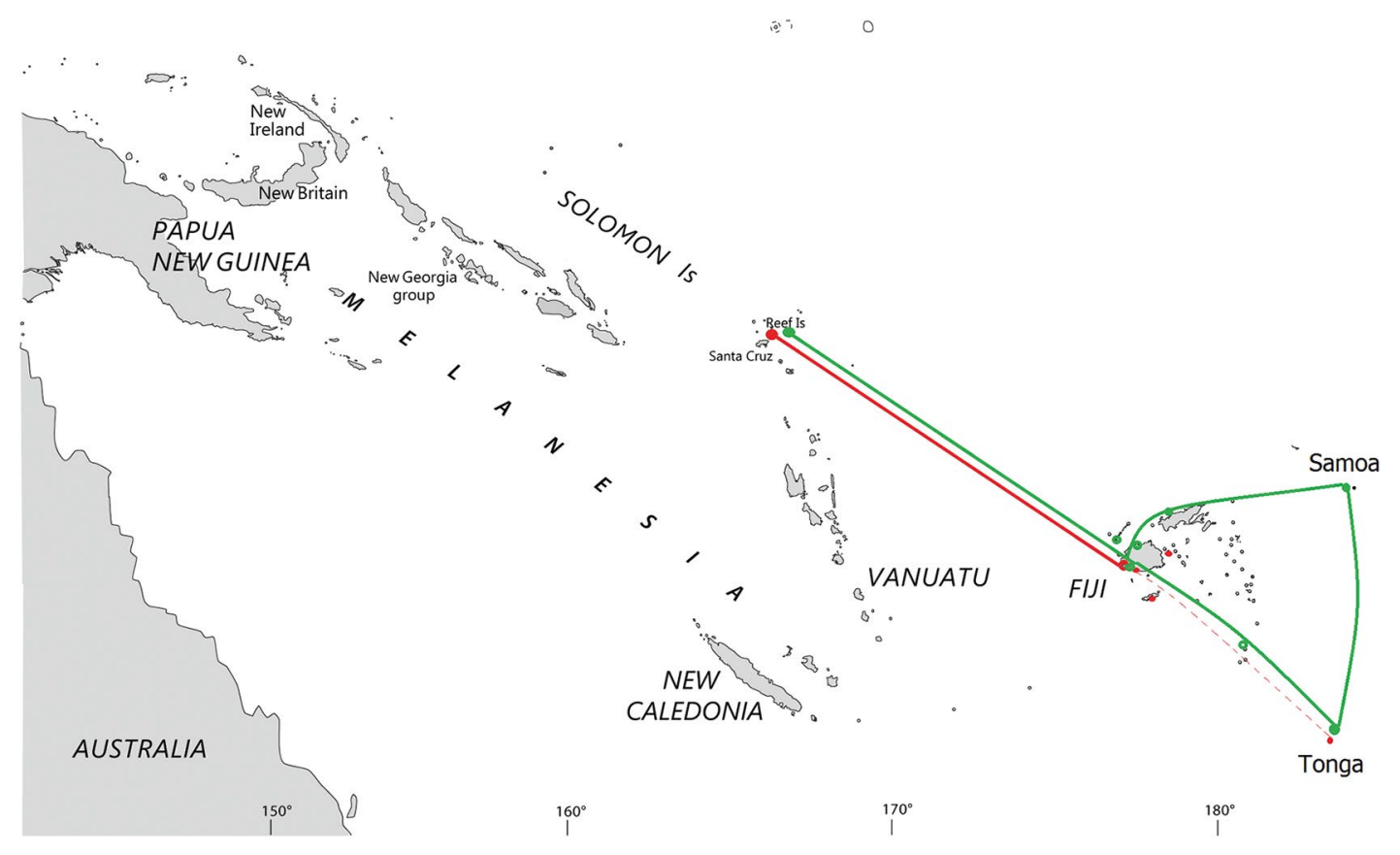

Figure 16.6. General view of the routes of Corpus A (in green) and B (in red).

The links to Solomons Lapita sites are used only as references. Of course other links might be traced to Vanuatu, or other archipelagos.

Source: Illustration by the author.

The correspondences between repetition of corpus and group markers show that only a few Lapita groups arrived in Samoa, maybe a maximum of three. One of these connections (in orange Figure 16.5) occurs only between northern Viti Levu and Samoa. Other motifs rather than markers in Samoa indicate the same results. As I have hypothesised in previous work (Noury 2011, 2013), a lot of Lapita motifs (mainly group markers) may indicate the identity or status of the person for whom the pottery was intended, and so we might be able to track the movements of Lapita people from motif repetition. The data indicate that the Samoan sites would have been settled by Lapita groups coming directly from the north of Fiji (only from Corpus A, orange 
arrow on Figure 16.5). On the other hand, eastern Fiji and Tonga would have been colonised by people coming from western Viti Levu. These people belonged to both Corpus A and B, but it was mainly Corpus A that colonised eastern Fiji and Ha'apai in Tonga (blue arrows in Figure 16.5). Groups belonging to Corpus $B$ that reached Tonga were much less numerous, probably in the same proportion as those found in Naitabale, given the chemical composition of sherds (89 per cent) from the latter site, but this remains to be confirmed by further analysis, especially in Nukuleka. This suggests that Bourewa was a major 'bridgehead' or nodal settlement for the groups from Corpus B. It would have been the main site of occupation, but it seems that their pottery rarely made it beyond the local area to other sites. It could have been the case, for instance, that pottery was being made for marriage ceremonies or for burial purposes, as in the case of Teouma in Vanuatu (Dickinson et al. 2013). If we consider the quantity of various group markers from sites, we might expect that the more numerous markers at Bourewa and Nukuleka represented the more populous or the more active potters over time. As these sites are also the sites where Corpus B is well represented, and sites with only Corpus A sherds contain much fewer sherds, we might also suppose that it was Lapita groups of Corpus B who were more populous than those of Corpus A. As a cause and a consequence, Samoa may only have been sparsely populated. Due to the small quantity of sherds from Futuna, it is very speculative to try and determine which corpus it belongs to, but at first estimate, we can also propose Corpus $\mathrm{A}$ occupation, with no trace of Corpus B.

New motifs and new group markers seem to have been very largely created in the Fiji Islands, with a lesser number in Tonga. As I have also previously argued (Noury 2013), creation of a new motif (and especially a new group marker) would have occurred at the time of the creation of a new lineage or a new colony. It implies that more new groups were created in Fiji and southern Tonga than elsewhere, probably due to greater population numbers. This also implies that the duration of Samoan occupation was very short and/or there was very little interaction with other Lapita groups.

These interpretations of the results are valid assumptions only if we think (as I do) that Lapita motifs were mostly markers of identity. There are two main 'styles' of Lapita designs, Corpora $\mathrm{A}$ and $\mathrm{B}$. We can imagine a temporal sequence of colonisation: first one corpus, then a second. However, the problem is that the dates of Lapita sites have recently been completely revised and there are minimal temporal differences in first settlement dates across Eastern Lapita (Burley et al. 2015; Nunn and Petchey 2013). For Nukuleka in particular the range of dates is very short, which would mean that the two corpora appeared in two colonisation waves over a very short time period. It seems more reasonable to me to imagine that a site such as Nukuleka, with its short-term occupation, would have been occupied by several different groups simultaneously in the same short time span rather than in two separate events.

Ever since the publication of Green (1979:44), an Eastern Lapita style has been recognised in Fiji and beyond in Samoa and Tonga. However, it seems that an Eastern Lapita Province, in terms of pottery motifs, does not in fact exist: the decay of motifs is just an impression generated through the presence of fewer groups, and the prominent part played by Corpus A's groups in Fiji and Polynesia. But some sites, such as Bourewa and to a lesser extent Nukuleka, contain mostly Corpus B groups. If these sites—especially Bourewa-had been included in Green's analysis, it would have produced different results; Bourewa's sherds would have looked like Western Lapita sherds. Based on the statistical study of isolated motifs and shapes of pots, it has been determined that there were stylistic differences between eastern and western Fiji (Burley et al. 2002; Clark and Murray 2006). Burley even suggested that eastern Fiji may have been colonised by Nukuleka potters from Tonga in a late phase of the Lapita period. This seemed to be the case when studying Lapita designs (Burley et al. 2002), but it was not supported by studies of the other archaeological 
artefacts (Clark and Murray 2006:108-109). Our present model explains why it seems that Nukuleka was a prominent site in terms of Lapita motifs. However, it was not to do with the site being older but rather because it was settled by multiple groups. As many Lapita corpora and groups were mixed in statistical approaches, there was a strong bias. In eastern Fiji, there were simply fewer Lapita groups, and fewer samples of Corpus B. As Corpus B was only prevalent in some western Fijian sites (Bourewa), and only a little in Tonga, it gives the impression that there was: 1) a differentiation (and even a decay) between western and eastern Fiji, and 2) there were also differences between eastern Fiji and Tonga. My research suggests that there were only different Lapita groups and corpora. This means that potentially, someone may yet discover archaeological sites with full 'eastern Fijian' traits in the western part of the archipelago.

\section{Conclusion}

This paper outlines a new approach to studying Lapita designs using the Eastern Lapita sites as a test case. As demonstrated earlier (Noury 2013), Lapita designs can be divided into several 'groups' that are not distributed in the same way across the Lapita world. These groups are themselves included within two main corpora. These have particular motifs that can help us to track how groups moved between islands. Most Lapita motifs can be attributed to a specific corpus, and sometimes more precisely to a specific group within that corpus.

Results for Eastern Lapita show that the Lapita designs are mostly dominated by Corpus A, except in a few sites in western Fiji (Bourewa is the best example). The groups included in Corpus B extended primarily across western Fiji, to a small extent in eastern Fiji and southern Tonga, but not at all in Samoa and probably not in Futuna. Looking closely at the group markers and other associated motifs, one can track a few groups, which seems to give a general view of the process of colonisation of the region. One or two groups only of Corpus A seemed to have colonised Samoa, probably in small communities. Tonga was also colonised mostly by groups of Corpus A, but in association with a few groups of Corpus B, probably coming from Viti Levu. Some new group markers (and other motifs associated with them) have been recorded there, meaning that several groups have been formed or created in Fiji and southern Tonga only. At this stage, few traces of these new groups have been discovered outside the region.

These results and hypotheses suggest that in the past several different groups moved about within the whole area, sometimes coexisting together on the same site. Movement was quite complex, and this shows that designs cannot be studied by statistics that are based on entire collections without considering the internal peculiarities of the Lapita groups. However, these results must be considered with caution. The data used are very heterogenous and some collection sizes are very small. More decorated sherds must be analysed in the future to test the conclusions suggested here.

\section{Acknowledgements}

I want to greatly thank Stuart Bedford for his encouragement to continue this research, which had stopped for a while, and for the honour of being invited to lead the 'Lapita designs' session in partnership with Scarlett Chiu at the Eighth International Lapita Conference. I also appreciated the positive and encouraging comments from Matthew Spriggs and his kind and warm hospitality in Vila. This pleasant welcome, added to the natural hospitality of the ni-Vanuatu people and the Vanuatu Cultural Centre, allowed this paper to be presented. All figures and tables were produced by the author. 


\section{References}

Anderson, A. and G. Clark 2006. Fieldwork in southern Viti Levu and Beqa Island. In G. Clark and A. Anderson (eds), The early prehistory of Fiji, pp. 117-118. Terra Australis 31. ANU E Press, Canberra. doi.org/10.22459/ta31.12.2009.05.

Anson, D. 1983. Lapita pottery of the Bismarck Archipelago and its affinities. Unpublished PhD thesis, University of Sydney, Sydney.

Anson, D. 1986. Lapita pottery of the Bismarck Archipelago and its affinities. Archaeology in Oceania 21(3):157-165. doi.org/10.1002/j.1834-4453.1986.tb00144.x.

Best, S. 1984. Lakeba: The prehistory of a Fijian island. Unpublished PhD thesis, University of Auckland, Auckland.

Burley, D.V. 1991. Archaeological research in the Ha'apai Islands Kingdom of Tonga: A report on the 1990 field season. Unpublished manuscript on file, Department of Archaeology, Simon Fraser University, Burnaby.

Burley, D.V. 1992. Archaeological research in the Ha'apai Islands Kingdom of Tonga: A report on the 1991 field season. Unpublished manuscript on file, Department of Archaeology, Simon Fraser University, Burnaby.

Burley, D.V. 1994. Settlement pattern and Tongan prehistory reconsideration from Ha'apai. Journal of the Polynesian Society 103(4):379-411.

Burley, D.V. 2012. Exploration as a strategic process in the Lapita settlement of Fiji: The implications of Vorovoro Island. Journal of Pacific Archaeology 3(1):22-34.

Burley, D.V. and W.R. Dickinson 2001. Origin and significance of a founding settlement in Polynesia. Proceedings of the National Academy of Sciences 98(20):11829-11831. doi.org/10.1073/ pnas. 181335398.

Burley, D.V., A. Storey and J. Witt 2002. On the definition and implications of Eastern Lapita ceramics in Tonga. In S. Bedford, C. Sand and D. Burley (eds), Fifty years in the field: Essays in honour and celebration of Richard Shutler Jr's archaeological career, pp. 213-226. New Zealand Archaeological Association Monograph 25. New Zealand Archaeological Association, Auckland.

Burley D.V., A. Barton, W.R. Dickinson, S.P. Connaughton and K. Taché 2010. Nukuleka as a founder colony for west Polynesian settlement: New insights from recent excavations. Journal of Pacific Archaeology 1(2):128-144.

Burley, D.V., K. Edinborough, M. Weisler and J.-x. Zhao 2015. Bayesian modeling and chronological precision for Polynesian settlement of Tonga. PloS One 10(3):e0120795. doi.org/10.1371/journal. pone. 0120795 .

Chiu, S. 2003. The socio-economic functions of Lapita ceramic production and exchange: A case study from site WKO013A, Koné, New Caledonia. Unpublished PhD thesis, University of California, Berkeley.

Chiu, S. 2005. Meanings of a Lapita face: Materialized social memory in ancient house societies. Taiwan Journal of Anthropology 3(1):1-47.

Chiu, S. 2007. Detailed analysis of Lapita face motifs: Case studies from Reef/Santa Cruz Lapita sites and New Caledonia Lapita Site 13A. In S. Bedford, C. Sand and S.P. Connaughton (eds), Oceanic explorations: Lapita and Western Pacific settlement, pp. 241-264. Terra Australis 26. ANU E Press, Canberra. doi.org/10.22459/TA26.2007. 
Chiu, S. 2010. Lapita pottery of the Reef/Santa Cruz Islands, southeast Solomon Islands. In C. Sand and S. Bedford (eds), Lapita: Ancêtres Océaniens/Oceanic ancestors, pp. 118-119. Musée du quai Branly and Somogy, Paris.

Chiu, S. and C. Sand 2005. Recording of the Lapita motifs: Proposal for a complete recording method. Archaeology in New Zealand 48(2):133-150.

Clark, G. and A.J. Anderson 2001. The pattern of Lapita settlement in Fiji. Archaeology in Oceania 36(2):77-88. doi.org/10.1002/j.1834-4453.2001.tb00480.x.

Clark, G. and T. Murray 2006. Decay characteristics of the Eastern Lapita design system. Archaeology in Oceania 41(3):107-117. doi.org/10.1002/j.1834-4453.2006.tb00619.x.

Cochrane, E.E. 2002. Explaining the prehistory of ceramic technology on Waya Island, Fiji. Archaeology in Oceania 37:37-50. doi.org/10.1002/j.1834-4453.2002.tb00499.x.

Cochrane, E.E., S. Matararaba and E. Nakoro 2007. Lapita and later archaeology of the Malolo and Mamanuca Islands, Fiji. The Journal of Island and Coastal Archaeology 2(2):245-250. doi.org/10.1080/ 15564890701622896.

Davidson, J.M., E. Hinds, S. Holdaway and B.F. Leach 1990. The Lapita site of Natunuku, Fiji. New Zealand Journal of Archaeology 12:121-155.

Dickinson, W.R. and P.D. Nunn. 2013. Petrography of sand tempers in Lapita potsherds from the Rove Peninsula, Southwest Viti Levu, Fiji. Journal of Pacific Archaeology 4(1):15-31.

Dickinson, W.R., S. Bedford and M. Spriggs 2013. Petrography of temper sands in 112 reconstructed Lapita pottery vessels from Teouma (Efate): Archaeological implications and relations to other Vanuatu tempers. Journal of Pacific Archaeology 4(2):1-20.

Green, R.C. 1976. Lapita sites in the Santa Cruz group. In R.C. Green and M.M. Cresswell (eds), Southeast Solomon Islands cultural history: A preliminary survey, pp. 245-265. Royal Society of New Zealand Bulletin 11. Royal Society of New Zealand, Wellington.

Green, R.C. 1979. Lapita. In J.D. Jennings (ed.), The prehistory of Polynesia, pp. 27-60. Harvard University Press, Cambridge, Mass. doi.org/10.4159/harvard.9780674181267.c3.

Green, R.C. 1990. Lapita design analysis: The Mead system and its use, a potted history. In M. Spriggs (ed.), Lapita design, form and composition: Proceedings of the Lapita Design Workshop, Canberra, December 1988, pp. 33-52. Occasional Papers in Prehistory 19. Department of Prehistory, RSPacS, The Australian National University, Canberra.

Kay, R. 1984. Analysis of archaeological material from Naigani. Unpublished MA thesis, University of Auckland, Auckland.

Kirch, P.V. 1988. Problems and issues in Lapita archaeology. In P.V. Kirch and T. Hunt (eds), Archaeology of the Lapita Cultural Complex: A critical review, pp. 158-165. Thomas Burke Memorial Washington State Museum Research Report No 5. Burke Museum, Seattle.

Mead, S.M. 1975. The decorative system of the Lapita potters of Sigatoka, Fiji. In S.M. Mead, L. Birks, H. Birks and E. Shaw (eds), The Lapita pottery style of Fiji and its associations, pp. 19-43. The Polynesian Society Memoir No 38. Polynesian Society, Wellington.

Noury, A. 1998. Les décors des poteries Lapita du Vanuatu. Unpublished MA thesis, Université Paris-I Panthéon Sorbonne, Paris. 
Noury, A. 2000. Les décors Lapita en Mélanésie et en Polynésie Occidentale, analyses-test de deux collections de Nouvelle-Calédonie: La collection Gifford et Shutler de Lapita (WKO013) et la collection Golson de Vatcha (KVO003). Unpublished DEA thesis, Université Paris-I Panthéon Sorbonne, Paris.

Noury, A. 2005. Le reflet de l'âme Lapita. Essai d'interprétation des décors des poteries Lapita en Mélanésie et en Polynésie Occidentale entre 3300 et 2700 avant le présent. Noury éditions, Versailles.

Noury, A. 2011. De la poterie Lapita à la Parole des premières sociétés d'Océanie: Les décors et la société Lapita. Thèse de Doctorat, Université de La Rochelle, La Rochelle.

Noury, A. 2013. Le Lapita. À l'origine des sociétés d'Océanie. Lulu, Paris.

Noury, A. and J.-C. Galipaud 2011. Les Lapita: Nomades du Pacifique. IRD Éditions, Marseille. doi.org/ 10.4000/books.irdeditions.653.

Nunn, P.D. and F. Petchey 2013. Bayesian re-evaluation of Lapita Settlement in Fiji: Radiocarbon analysis of the Lapita occupation at Bourewa and nearby sites on the Rove Peninsula, Viti Levu Island. Journal of Pacific Archaeology 4(2):21-34.

Nunn, P.D., T. Ishimura, W.R. Dickinson, K. Katayama, F.R. Thomas, R., Kumar, R and T. Worthy 2007. The Lapita occupation at Naitabale, Moturiki Island, Central Fiji. Asian Perspectives 46(1):96-132. doi.org/10.1353/asi.2007.0009.

Petchey F.J. 1995. The archaeology of Kudon: Archaeological analysis of Lapita ceramics from Mulifanua, Samoa and Sigatoka, Fiji. Unpublished MA thesis, University of Auckland, Auckland.

Poulsen, J. 1987. Early Tongan prehistory: The Lapita period on Tongatapu and its relationships. Two volumes. Terra Australis 12. Department of Prehistory, RSPacS, The Australian National University, Canberra.

Rogers, G. 1974. Archaeological discoveries on Niuatoputapu Island, Tonga. Journal of the Polynesian Society 83(3):308-348.

Sand, C. 1993. Données archéologiques et géomorphologiques du site ancien d'Asipani, Futuna (Polynésie occidentale). Journal de la Société des Océanistes 96(2):117-144. doi.org/10.3406/jso.1993.2928.

Sharp, N.D. 1988. Style and substance: A reconsideration of the Lapita decorative system. In P.V. Kirch and T.L. Hunt (eds), Archaeology of the Lapita Cultural Complex: A critical review, pp. 61-81. Thomas Burke Memorial Washington State Museum Research Report No. 5. Burke Museum, Seattle.

Sheppard, P.J., S. Chiu and R. Walter 2015. Re-dating Lapita movement into Remote Oceania. Journal of Pacific Archaeology 6(1):26-36.

Siorat, J.-P. 1988. Le décor céramique Lapita de Nouvelle-Calédonie. Unpublished MA thesis, Université Paris-I, Panthéon Sorbonne, Paris.

Spriggs, M. 1990. The changing face of Lapita: Transformation of a design. In M. Spriggs (ed.), Lapita design, form and composition. Proceedings of the Lapita Design Workshop, Canberra, December 1988, pp. 83-122. Occasional Papers in Prehistory 19. Department of Prehistory, RSPacS, The Australian National University, Canberra. 
This text is taken from Debating Lapita: Distribution, Chronology, Society and Subsistence, edited by Stuart Bedford and Matthew Spriggs, published 2019 by ANU Press,

The Australian National University, Canberra, Australia.

doi.org/10.22459/TA52.2019.16 